\title{
Potentials of Bambusa vulgaris Grown in Southeast Nigeria for the Manufacture of Wood-Cement Composite Panels
}

\author{
Eugene O. Onuorah'1, Elias Chukwunonso Nnabuife'2, Joseph T. Nwabanne ${ }^{3 *}$ \\ ${ }^{1}$ Department of Metallurgical and Materials Engineering, Nnamdi Azikiwe University, Awka, Nigeria \\ ${ }^{2}$ Department of Forestry and Wildlife, Nnamdi Azikiwe University, Awka, Nigeria \\ ${ }^{3}$ Department of Chemical Engineering, Nnamdi Azikiwe University, Awka, Nigeria \\ Email: ${ }^{*}$ joe nwabanne@yahoo.com
}

Received 11 May 2014; revised 25 June 2014; accepted 10 July 2014

Copyright (C) 2014 by authors and Scientific Research Publishing Inc.

This work is licensed under the Creative Commons Attribution International License (CC BY).

http://creativecommons.org/licenses/by/4.0/

(c) (i) Open Access

\section{Abstract}

In this work, the potentials of Bambusa vulgaris grown in southeast Nigeria for the manufacture of wood-cement composite panels were studied. Representative culms of Bambusa vulgaris were collected from a 4-year-old stand at lower Anambra river basin, southeast, Nigeria. Fiber morphological properties and proximate chemical analysis were determined in accordance with the provisions of the Technical Association of the Pulp and Paper Industries (TAPPI, 1998). Fiber slenderness ratio was $160.95: 1$, component solubility of $3.09,5.60$, and 19.8 percent for cold water soak for $24 \mathrm{hrs}$; hot water soak at $80^{\circ} \mathrm{C}$ for $1 \mathrm{hr}$, and $1 \% \mathrm{NaOH}$ soak for $24 \mathrm{hrs}$ respectively. Composite panels were made at $1200 \mathrm{~kg} / \mathrm{m}^{3}$ and $800 \mathrm{~kg} / \mathrm{m}^{3}$ density levels with flakes of different soak treatments (untreated/control; cold water soak for $24 \mathrm{hrs}$; water at $80^{\circ} \mathrm{C}$ soak for $1 \mathrm{hr}$ and $1 \%$ $\mathrm{NaOH}$ soak for $24 \mathrm{hrs})$ at variable cement/B. vulgaris mix ratios $(1: 1,1.5: 1,2: 1,2.5: 1$ and 3:1 $\mathrm{wt} / \mathrm{wt}$ ) with $3 \% \mathrm{CaCl}_{2}$ as accelerator applied to the wood furnish before cement mixing. Prepared furnish was subjected to initial pre-pressing of $0.5 \mathrm{~N} / \mathrm{mm}^{2}$ and final consolidation of $1.4 \mathrm{~N} / \mathrm{mm}^{2}$ retained for 24 hrs. Panels were sampled and tested after 28 days for Modulus of Rupture (MOR) and Modulus of Elasticity (MOE) in bending and for water absorption (WA) and thickness swelling (TS) due to a 24-hr water soak. Test was in accordance with provisions of American Standard for Testing of Materials (ASTM-1998). Properties ranged from a low of 25.00 to $75.45 \mathrm{~N} / \mathrm{mm}^{2}$ for MOR; 4128 to $15,065 \mathrm{~N} / \mathrm{mm}^{2}$ for MOE; 15.01 to 36.11 percent for WA and 3.04 to 12.72 percent for TA. Effect of production mix on properties was determined using factorial analysis. Except for composite density whose effect was not significant at $0.05 \%$ level, all production mix was found significant at $0.01 \%$ level at the second order level of interactions. All panels met minimum property requirements of American National Standard Institute 208-2-1994 and 208-1-1993, British Standard (BS 5669, 1979) and Malaysian Standard (MS 934, 1984).

*Corresponding author.

How to cite this paper: Onuorah, E.O., Nnabuife, E.C. and Nwabanne, J.T. (2014) Potentials of Bambusa vulgaris Grown in Southeast Nigeria for the Manufacture of Wood-Cement Composite Panels. Journal of Minerals and Materials Characterization and Engineering, 2, 363-373. http://dx.doi.org/10.4236/jmmce.2014.25041 


\title{
Keywords
}

\author{
Fiber Characteristics, Proximate Analysis, Soak Treatments, Panel Density, Cement/B. vulgaris Mix \\ Ratios, Composite Properties
}

\section{Introduction}

Concerns for global environmental degradation as a result of deforestation and use of fossil fuels as well as reported pockets of deficit in supply of forest timber based industrial fiber in some parts of the world have created a need for the search for alternative products that are both sustainable and environmentally friendly [1]-[5]. Wood/lignocellulosic based composites have been found to be particularly attractive primarily because of their high potential for value addition, sustainable supply, low cost, non carcinogenic and high specific strength properties relative to other competing materials [6]-[8]. Again wood-cement composites have the added advantage of resistance to corrosion, biodegradation, fire and flame spread. As a product, they exhibit also high levels of thermal and sound insulation [8] [9].

In general, properties of wood/lignocellulosic composite panels are known to have high correlations with the characteristics of the constituent raw materials, their distribution within the matrix and interactions of the relevant production variables [10]-[14]. Industrial utilization of bamboo, agricultural lignocellulosics and wood-residues has been reported to have the high multiplier effect on the economy because it is sustainable, and environmentally friendly, has the high wealth generation potential and creates employment [8] [15].

Available records indicate that there are over 1200 species of bamboo found in 70 genera [16]. Bambusa vulgaris belongs to the bambusoidae sub-family of the Graminaceae family and it is a perennial woody plant that matures in 3 to 6 years [16]. Bambooes are reported to be the fastest growing plant on earth sometimes producing three times more biomass than the fastest growing tree [16]-[18]. One of the known draw backs that had delayed private sector investment in industrial timber plantation in developing economies is the long gestation period [5]. Since bamboo is a short rotation crop relative to trees, it can be integrated into agroforestry and environmental forestry in order to supply industrial fiber. It is thus imperative that efficient and cost effective industrial use of bamboo biomass must be found.

Presently the use of bamboo in the production of industrial products in Nigeria and indeed sub-saharan Africa is in its infancy. There are obstacles in the production and utilization of wood cement composites. One of such obstacles is the adverse effects of some wood constituents, notably extractives and soluble polysaccharides on the hydration and curing of cement [5] [16] [19]-[21]. Some of the process methods which had been used to ameliorate the adverse effects of wood constituents and extractives on the setting of cement were the use of various leaching/soaking regimes and incorporation of additives that will accelerate hydration [10] [12] [19] [20]. Other impediments had been the increasing cost of the composite as the cement-wood ratio was increased as the cement costs more than the lignocellulosic furnish. Also, it is often necessary to balance the improvements in physical and mechanical properties as composite panel density is increased with the limitations of denser panels as weight of the composite can become a limiting factor in certain constructions.

The objective of this study were to evaluate the effects of cement/Bumbusa vulgaris mix ratios, chip/flake soak treatments and composite panel densities on the Modulus of Rupture (MOR) and Modulus of Elasticity (MOE) in Bending; and the water absorption and thickness swelling properties of the resultant composite panel.

\section{Materials and Methods}

\subsection{Material Collection and Preparation}

Representative culms of Bambusa vulgaris were obtained from a four year old bamboo stand at Nteje $\left(6^{\circ} 16^{\prime \prime} \mathrm{N}\right.$ latitude and 6 40 "E longitude) in Oyi Local Government Area, Anambra State, southeast, Nigeria. The culms were collected at 10, 20, 50, 70 and 90 percent of the full length for each stick of bamboo. Identification was done using floral parts after the method reported by some authors [22] [23]. The collected culms were allowed to dry in the open laboratory for 30 days at the end of which each culm was manually broken into $100 \mathrm{~mm}$ by 150 $\mathrm{mm}$ by wall thickness. The resultant discs were further reduced to flakes of average $50 \mathrm{~mm}$ by $16 \mathrm{~mm}$ by 1.9 
$\mathrm{mm}$ in a pallmann knife ring flaker. The flakes were further allowed to dry in the open laboratory for two weeks at laboratory conditions. At the end of this period, the flakes were collected and stored in vapour impermeable bags and kept for use. Cement used was ordinary Portland cement sold in $50 \mathrm{~kg}$ bags and commonly available in Nigerian market.

\subsection{Soak Treatment}

Representative samples of the flakes were either marked and used untreated, to be used after soaking in distilled water for $24 \mathrm{hrs}$ at room conditions; soaked in distilled water at a temperature of $80^{\circ} \mathrm{C}$ or soaked in one percent Sodium Hydroxide solution ( $\mathrm{NaOH}$ ) for 24 hrs at room conditions. At the end of each soak treatment, the leachants were allowed to drain off and the flakes washed immediately with copious supply of distilled water. The soaked and unsoaked particles were conditioned in a conditioning chamber at $20^{\circ} \mathrm{C} \pm 2^{\circ} \mathrm{C}$ and $65 \% \pm 1 \%$ Relative humidity (R. H.) and stored in vapour impermeable bags ready for use.

\subsection{Chemical Analysis}

Proximate chemical analysis was conducted in compliance with the provisions of the standard Test Methods of the Technical Association of the Pulp and Paper Industry [24]. Representative flakes randomly selected were Wiley milled to powder, screened through a 60 BSS mesh and powder that passed through 60 BSS mesh but retained on 80 were used for the analysis.

\subsection{Fiber/Culm Anatomical and Physical Characteristics}

Representative flakes were selected and reduced to splinters. The splinters were macerated/pulped in $1 \% \mathrm{NaOH}$ conc. at $80^{\circ} \mathrm{C}$ for $10 \mathrm{hrs}$. At the end of the above period, the resultant fiber bundles were washed in distilled water and the fiber suspension subsequently subjected to further defiberization in the presence of glass beads with the aid of vigorous agitation (Onuorah, 2005). One hundred and thirty (130) representative fiber samples were selected, stained with safarin- $C$ and mounted on slides and viewed at $100 \times$ magnifications using a microscope. The fiber dimensions (length, diameter, lumen width and cell wall thickness) were measured wet with the aid of stage and occular micrometer scales [15] [25]. The averages and standard deviations were determined.

Thirty representative culms were taken and the culm lengths, culm diameter and culm wall thickness measured using linear tapes and micro gauge. The specific gravity was determined in accordance with the provisions of ASTM D2395-89 [26]. The means and standard deviations were determined and recorded.

\subsection{Board Making}

Appropriate quantity (oven dry weight basis) of the B. vulgaris flakes for each soak treatment type was measured out based on cement-bamboo flakes mix ratio. The exact quantity to be used for each board type was determined in preliminary studies which took into cognizance the soak treatment type/mix ratio/composite density combinations. The required quantity of water in litres $(Q)$ needed for the production of each board was determined using Equation (1)

$$
Q=0.35 C+(0.30-M) W
$$

where $C$ = cement wt in $\mathrm{kg}$; $M$ = fiber/flake moisture content and $W=$ oven dry wt of fiber/flakes as reported by Erakhrumen [7]. Production variables used were as in Table 1.

The production constants were as follows: (all pressing was done cold i.e. absence of external heat)

1) Prepressing pressure of $0.5 \mathrm{~N} / \mathrm{mm}^{2}$ before final consolidation.

2) Final press pressure of $1.4 \mathrm{~N} / \mathrm{mm}^{2}$ for 24 hrs.

3) Curing of the pressed composite took place inside a vapour impermeable bag over a 28-day period.

4) Use of $6 \mathrm{~mm}$ thick metal stops placed on opposite sides of the metal caul/formed furnish.

5) Addition of $3 \%$ of calcium chloride (wt/wt cement basis) to weighed flakes before addition of cement.

6) Use of $19 \mathrm{~mm}$ plywood covered with thin polythene as the top platen.

Mixed furnish for each composite panel was formed on top of a metal cual whose surfaces had been previously covered with a thin polythene sheet while the top of the formed furnish was covered with $19 \mathrm{~mm}$ plywood whose surface had been covered with same polythene. Opposite each side of the length of the caul carry- 
Table 1. Design of variable production mix used in the manufacture of cement-Bambusa vulgaris composite panels.

\begin{tabular}{|c|c|c|c|c|c|c|}
\hline \multirow{3}{*}{ Density $\mathbf{k g} / \mathbf{m}^{3}$} & \multirow{3}{*}{ Soak treatment ${ }^{\mathrm{a}}$} & \multicolumn{5}{|c|}{ Cement-B. vulgaris flake mix ratio ${ }^{k}$} \\
\hline & & $1: 1$ & $1: 5$ & $2: 1$ & 2:5:1 & $3: 1$ \\
\hline & & \multicolumn{5}{|c|}{ No of boards produced } \\
\hline 1200 & Control & 2 & 2 & 2 & 2 & 2 \\
\hline 1200 & Cold water & 2 & 2 & 2 & 2 & 2 \\
\hline 1200 & Hot water & 2 & 2 & 2 & 2 & 2 \\
\hline 1200 & $1 \% \mathrm{NaOH}$ & 2 & 2 & 2 & 2 & 2 \\
\hline 800 & Control & 2 & 2 & 2 & 2 & 2 \\
\hline 800 & Cold water & 2 & 2 & 2 & 2 & 2 \\
\hline 800 & Hot water & 2 & 2 & 2 & 2 & 2 \\
\hline 800 & $1 \% \mathrm{NaOH}$ & 2 & 2 & 2 & 2 & 2 \\
\hline
\end{tabular}

${ }^{\mathrm{k}}$ Two composite panels were made per production mix from which two test specimens per panel were sampled for testing. Control = unsoaked flakes; cold water = unheated distilled water used for soaking the flakes for 24 hrs at room conditions; hot water = flakes soaked in hot water at $80^{\circ} \mathrm{C}$ for one hour; $1 \% \mathrm{NaOH}=$ flakes soaked in $1 \%$ concentration of $\mathrm{NaOH}$ for 24 hrs at room conditions; ${ }^{a}$ Except for the control all soak treatments were immediately followed by rapid but instantaneous washing in water in order to remove leachants and/or unspent chemicals.

ing the furnish but besides the furnish was placed a $6 \mathrm{~mm}$ metal stop. At the end of the curing period the panels were trimmed $0.5 \mathrm{~mm}$ from the edges in order to remove areas that were not properly consolidated during pressing.

\subsection{Board Testing}

The composite panels were sampled and tested in accordance with the provisions of ASTM D1037-96 [26]. The location of each test specimen in each composite panel was determined with the aid of a table of random numbers. All test specimens were conditioned in a controlled chamber at $20^{\circ} \mathrm{C} \pm 2{ }^{\circ} \mathrm{C}$ and $65 \% \pm 1 \%$. Relative humidity (R.H.) was for two weeks before testing.

Properties tested were the Modulus of Rupture (MOR) and Modulus of Elasticity (MOE) in Bending; the water absorption (WA) and thickness swelling (TS) due to a 24 hours horizontal water soak. There were a total of 4Nos tests for each production mix thus making a total of 160 Nos tests for each property. The reported properly value represents weighted average of four test samples at each production mix (mix ratio/soak/density interaction).

\subsection{Statistical Analysis}

A complete randomized experiment was designed at which the effects of the variable production mix (5 Nos mix-ratios, 4 Nos soak types and 2 Nos composite densities) and all possible interactions were determined. The levels of significant effects of the main variables, their first order interaction and second order interaction were determined using factorial analysis [27]. The mean property values at appropriate production mix were also determined.

\section{Results and Discussion}

\subsection{Bambusa vulgaris Properties}

Table 2 presents the fiber morphological characteristics, the culm features and physical characteristics of the mature $B$. vulgaris grown in Nteje, lower Anambra river basin, southeast, Nigeria along side of similar features for bambooes globally, sugarcane bagasse, decidous hardwoods and coconut coir fiber globally as reported in the literature [28] [29]. These are the competing woody and non-woody fiber sources for composites. The fiber 
Table 2. Fiber characteristics and proximate chemical analysis of B. vulgaris (bamboo) grown in Anambra river basin, southeast, Nigeria as compares with other non wood and wood-based fiber sources used in composite industry.

\begin{tabular}{|c|c|c|c|c|c|c|}
\hline $\mathbf{S} / \mathbf{N}$ & Property & $\begin{array}{l}\text { B. vulgaris } \\
\text { used in the study }\end{array}$ & $\begin{array}{l}\text { Bambooes } \\
\text { globally }\end{array}$ & $\begin{array}{l}\text { Sugar cane } \\
\text { bagasse }\end{array}$ & $\begin{array}{l}\text { Deciduous } \\
\text { hardwoods }\end{array}$ & $\begin{array}{c}\text { Coconut } \\
\text { coir }\end{array}$ \\
\hline A. & Fiber dimensions & & & & & \\
\hline i. & Fiber length (mm) & $2.91(0.072)$ & $1.360-4.030$ & 1.7 & 1.25 & 1.0 \\
\hline ii. & Fiber dimeter $(\mu \mathrm{m})$ & $18.08(1.68)$ & $8.0-30.0$ & 20 & 25 & $10-20$ \\
\hline iii. & Lumen width $(\mu \mathrm{m})$ & $10.04(1.3)$ & $=$ & $=$ & $=$ & $=$ \\
\hline iv. & Cellwall thickness $(\mu \mathrm{m})$ & $3.98(0.27)$ & $=$ & $=$ & $=$ & $=$ \\
\hline $\mathrm{v}$. & Slenderness ratio & $160.95: 1$ & $135-175: 1$ & $85: 1$ & $50: 1$ & $=$ \\
\hline vi. & Culm diameter (cm) & $10.65(0.78)$ & $=$ & $=$ & $=$ & $=$ \\
\hline vii. & Culm wall thickness (cm) & $1.8(0.43)$ & $=$ & $=$ & $=$ & $=$ \\
\hline viii. & Chem. length & $30.43(1.65)$ & $=$ & $=$ & $=$ & $=$ \\
\hline ix. & Bamboo specific gravity & $0.68(0.08)$ & $=$ & $=$ & $=$ & 1.15 \\
\hline B. & Proximate chemical analysis & & & & & \\
\hline i. & Cold water solubility (\%) & $3.09(0.18)$ & $=$ & 3.42 & $=$ & $=$ \\
\hline ii. & Hot water solubility (\%) & $5.60(0.52)$ & 4.4 & 7.42 & & 5.25 \\
\hline iii. & $1 \% \mathrm{NaOH}$ solubility (\%) & $19.8(0.91)$ & $=$ & 32.2 & & \\
\hline iv. & Alcohol benzene (1:2 v/v) & $5.0(0.70)$ & 3.2 & 1.85 & $=$ & 3.0 \\
\hline v. & Ash (\%) & $2.51(0.36)$ & $1.7-5.3$ & $1.5-5$ & $<1.0$ & 2.22 \\
\hline vi. & Silicon (\%) & $=$ & $1.5-3$ & $0.7-3$ & $<1.0$ & $=$ \\
\hline vii. & Pentosan (\%) & $17.12(0.33)$ & $15-26$ & $27-33$ & $19-26$ & $=$ \\
\hline viii. & Cellulose (\%) & $53.64(0.87)$ & $=$ & $=$ & $=$ & 43 \\
\hline ix. & Hellocellulose (\%) & 62.9 & $57-66$ & $49-62$ & $54-61$ & $=$ \\
\hline $\mathrm{x}$. & Lignin (\%) & $25.88(0.43)$ & $21-31$ & $19-24$ & $23-30$ & 45 \\
\hline
\end{tabular}

(1) Fiber Dimensions are the weighted average of 130 fiber measurements. (2) Information on deciduous words and other non wood species used in this table are from Hunter (2001) and Asasutjarit (2005).

morphological properties and the density of the bamboo compare favourably with those of other woody and non-wood species used in the production of wood-cement composites in other countries. Of particular interest is the fiber slenderness ratio of 160.95:1 which is within the range of 135 to 175:1 reported for all species of bamboo [29] and found to be greater than 85:1 for sugar-cane bagasse; 50:1 for deciduous Hardwood species and 58.8:1 for matured coconut coir fiber [28] [29]. High slenderness ratio of fibers/particles has been accepted to enhance the binder utilization efficiency of wood-based composites with attendant property improvements [30].

The proximate chemical analysis results are also in Table 2 and are also presented along side those for bambooes, deciduous hardwood species, sugar cane bagasse and coconut coir, all globally. The chemical constituents as well as leachable components compare favourable with those of bambooes globally as well as other competing woody and non-woody fiber sources used for composite manufacture globally [6] [15] [28] [31]. Chew and his co-workers reported that the effects of soluble wood constituents on cement hydration and consequently on wood-cement composite panel properties can effectively be reduced by reducing the soluble sugars to as low as $0.28 \%$ [12]. One other effective means of reducing the effects of soluble constituents on hydration is the use of additives. Available records indicate that incorporating $\mathrm{CaCl}_{2}$ above $3 \%$ (cement wt basis) in furnish mixtures above 2:1 cement wood ratio (wt/wt—on oven dry wt wood basis) maybe adequate in creating optimal hydration conditions for effective bonding and optimal composite panel properties [5] [20] [32]. 


\subsection{Composite Panel Properties}

Table 3 presents the results of Modulus of Rupture (MOR) and Modulus of Elasticity (MOE) in bending as well as the water absorption (WA) and thickness swelling (TS) due to a 24 hrs horizontal water soak. Of the eighty (80 Nos) composite panels produced in this study representing all possible combination of production mix, the average property ranges from 25.0 to $73.45 \mathrm{~N} / \mathrm{mm}^{2}$ for MOR; 4128 to 15,065 N/mm ${ }^{2}$ for MOE; $15.01 \%$ to 36.11\% for WA; and 3.04\% to $12.72 \%$ for TS due to a 24 -hr horizontal water soak. All properties met the specifications of American National Standard Institute-ANSI A208-1 and ANSI A 208-2; British standard specifications (BSS) [33]-[35] for wood chipboard and methods of test for particleboard BS5669 [35] and Malaysian Standard Specifications for wood cement Board MS 934 [36]. Table 4 presents the summary of factorial analysis on the effects of each manufacturing variable and all possible interactions of the variables on composite panel properties.

\subsection{Modulus of Rupture (MOR)}

At any given cement-B. vulgaris mix ratio (1:1, 1.5:1, 2:1, 2.5:1 and 3:1 wt/wt) and soak treatment (control, cold water, hot water and $1 \%$ concentration of $\mathrm{NaOH}$ ) the MOR increased as the ratio of the cement in the composite was increased (Table 3). This is in accord with the findings of other workers [8] [12]-[14] [32]. The effect of cement-B. vulgaris mix ratio on MOR was found significant at $5 \%$ level of probability in a factorial analysis while the effects of mix ratio at all possible levels of interactions of production mix used in the study were significant at $0.01 \%$ level. A possible explanation is that increase in composite binder content ensured more effective coverage of the surface area of the flakes and thus enhanced a strong inter fiber/flake bond until an optimum binder content will be reached beyond which increase in binder content will no longer bring additional enhancement in properties [8] [30]. Lingfei found optimal cement wood mix ratio to be 2.65:1 [20]. At any given cement-wood mix ratio and density, MOR was relatively enhanced as the soak treatment was changed from untreated/control to cold water, to hot water and to $1 \%$ concentration of $\mathrm{NaOH}$ treatments in that order (see Table 3). This is in agreement with the findings of other workers [8] [37]. The differences due to the effects of soak treatments were significant at $0.05 \%$ level but the effects of soak treatment interactions at all possible levels with other production mix were significant at $0.01 \%$ level (Table 4 ). The result is in conformity with known behaviour of wood-cement composites. It is generally understood that soluble sugars and extraneous materials interfer with cement hydration and consequently influence properties of composites. One accepted method of reducing the effects of these inhibitory constituents on cement hydration is the various soak treatment methods [10] [12] [20] [37].

The effects of Board density on the MOR of the composite panel was not found significant at $0.05 \%$ level of probability in a factorial analysis. This was not expected as high density implies higher compaction ratios for each given production mix (mix ratio and soak type). However, it is widely acknowledged that there is optimal compaction ratio above which further improvements in wood based composite properties as a result of compaction ratio no longer results in significant properties improvements [30]. The exact optimum for wood-cement boards found in the literature varied with the choice of lignocellulosic furnish, mix ratio, soak treatment, cement/water mix ratio, additive type and quantity, etc. But there appears to be a synergy between panel density and all other production mix at all possible levels of interactions (density/soak treatment, density/cement: wood mix ratio; density/soak type/cement: wood mix ratio) as their effects were all found significant at $0.01 \%$ level. The explanation may be that above $800 \mathrm{~kg} / \mathrm{m}^{3}$ effect due to soak type and/or cement: $B$. vulgaris mix ratio far out-weighs the effects due to density alone. It may also mean that differences in relative volume of the $B$. vulgaris flakes used in making the boards at all cement: wood ratios was insignificant taking into cognizance the weight of cement and average mean density of the bamboo relative to panel density.

\subsection{Modulus of Elasticity (MOE)}

At any given composite panel density and cement: B. vulgaris flakes mix ratio, the composite MOE in bending increased as the soak treatment was changed from unsoaked flakes/control to cold water soak to Hot water soak to $1 \%$ concentration of $\mathrm{NaOH}$ soak in that order (Table 3). At same level of soak treatment, the composite MOE increased as mix ratio was increased from 1:1 to 3:1 (Table 3). These are in agreement with the findings of other workers who used different lignocellulosic furnish [7] [8] [13] [14]. The effects of each production variable (density/soak treatment/cement: wood mix ratio) as well as all their possible interactions on MOE were all found 
Table 3. Properties of Bambusa vulgaris (bamboo)—cement composite panels as affected by variable production mix.

\begin{tabular}{|c|c|c|c|c|c|c|}
\hline \multirow{2}{*}{$\begin{array}{c}\text { Soak } \\
\text { treatment }\end{array}$} & \multirow{2}{*}{$\begin{array}{l}\text { Cement- } \\
\text { B. vulgaris mix } \\
\text { ratio (wt/wt) }\end{array}$} & \multirow{2}{*}{$\begin{array}{c}\text { Composite } \\
\text { panel } \\
\text { density } \mathrm{kg} / \mathrm{m}^{3}\end{array}$} & \multicolumn{2}{|c|}{ Mechanical properties } & \multicolumn{2}{|c|}{ Physical properties } \\
\hline & & & $\begin{array}{c}\text { Modulus of } \\
\text { rupture } \mathbf{N} / \mathbf{m m}^{2}\end{array}$ & $\begin{array}{c}\text { Modulus of } \\
\text { Elasticity N/mm² }\end{array}$ & $\begin{array}{c}\text { Water absorption } \\
\text { due to } 24 \text { hrs soak (\%) }\end{array}$ & $\begin{array}{l}\text { Thickness swelling due } \\
24 \text { hrs water soak (\%) }\end{array}$ \\
\hline \multirow[t]{5}{*}{ Control } & $1.0: 1$ & 1200 & $28.50(4.11)$ & $4876(3.7)$ & $34.50(5.0)$ & $12.72(3.6)$ \\
\hline & $1.5: 1$ & 1200 & $34.00(3.71)$ & $5029(4.0)$ & $29.11(4.8)$ & $10.02(3.1)$ \\
\hline & $2.0: 1$ & 1200 & $40.39(2.9)$ & $7094(3.5)$ & $26.42(5.1)$ & $8.95(3.1)$ \\
\hline & $2.5: 1$ & 1200 & $46.00(3.8)$ & $8303(4.2)$ & 27.11 (3.6) & 7.64 (4.1) \\
\hline & $3.0: 1$ & 1200 & $50.12(3.5)$ & $9111(2.9)$ & $25.50(4.2)$ & $5.21(2.6)$ \\
\hline \multirow[t]{5}{*}{ Control } & $1: 1$ & 800 & $25.00(4.0)$ & $4128(2.8)$ & $36.11(3.8)$ & $10.84(4.1)$ \\
\hline & $1.5: 1$ & 800 & $27.64(3.5)$ & $4324(3.5)$ & $34.40(4.1)$ & $7.64(5.0)$ \\
\hline & $2.0: 1$ & 800 & $31.00(3.2)$ & $5754(4.0)$ & $30.02(4.8)$ & $5.44(4.2)$ \\
\hline & $2.5: 1$ & 800 & $36.03(3.10)$ & 7182 (3.4) & $28.11(3.7)$ & 4.50 (3.7) \\
\hline & $3.0: 1$ & 800 & 41.15 (3.7) & 8389 (3.8) & $26.06(2.6)$ & $3.90(3.5)$ \\
\hline \multirow[t]{5}{*}{ Cold water } & $1.0: 1$ & 1200 & $33.50(5.0)$ & $6238(4.1)$ & $30.44(4.5)$ & $9.85(4.6)$ \\
\hline & $1.5: 1$ & 1200 & $39.67(4.4)$ & 7014 (3.9) & $27.51(7.0)$ & $7.08(4.8)$ \\
\hline & $2.0: 1$ & 1200 & $47.61(4.3)$ & $9800(3.5)$ & $25.13(3.1)$ & $6.11(4.1)$ \\
\hline & $2.5: 1$ & 1200 & $50.11(2.7)$ & $12,180(2.9)$ & $23.80(4.4)$ & $4.02(3.6)$ \\
\hline & $3.0: 1$ & 1200 & $56.12(4.8)$ & $13,300(5.0)$ & 22.00 (2.9) & $4.81(3.6)$ \\
\hline \multirow[t]{5}{*}{ Cold water } & $1.0: 1$ & 800 & 30.11 (3.3) & 4899 (1.5) & 32.62 (3.1) & $9.11(3.2)$ \\
\hline & $1.5: 1$ & 800 & 34.00 (3.1) & 5295 (2.8) & $28.96(2.7)$ & 7.53 (2.9) \\
\hline & $2.0: 1$ & 800 & $39.65(5.0)$ & $6611(2.1)$ & $26.41(4.6)$ & $5.68(2.7)$ \\
\hline & $2.5: 1$ & 800 & $45.80(3.6)$ & $7710(3.0)$ & $23.01(3.2)$ & $4.02(4.1)$ \\
\hline & 3.0:1 & 800 & $49.81(4.3)$ & $9245(3.2)$ & $20.85(3.0)$ & $3.48(3.7)$ \\
\hline \multirow[t]{10}{*}{ Hot water } & $1.0: 1$ & 1200 & $31.76(4.5)$ & 7746 (3.1) & $26.12(2.5)$ & $9.00(2.6)$ \\
\hline & $1.5: 1$ & 1200 & 40.01 (3.1) & 8821 (4.1) & 25.15 (1.8) & $8.141(2.3)$ \\
\hline & $2.0: 1$ & 1200 & $46.81(2.8)$ & $11,294(4.3)$ & $26.00(2.1)$ & $6.01(1.8)$ \\
\hline & $2.5: 1$ & 1200 & $51.11(4.1)$ & 13,203 (2.9) & $24.41(3.0)$ & 4.64 (1.9) \\
\hline & $3.0: 1$ & 1200 & $67.89(6.1)$ & $14,736(5.1)$ & 23.01 (1.9) & $4.01(3.0)$ \\
\hline & $1.0: 1$ & 800 & $30.06(3.0)$ & $6416(4.2)$ & $28.14(2.4)$ & 7.15 (2.7) \\
\hline & $1.5: 1$ & 800 & 38.02 (3.1) & 7917 (3.9) & $28.62(2.3)$ & $6.02(3.1)$ \\
\hline & $2.0: 1$ & 800 & $44.81(2.9)$ & $9721(4.7)$ & $24.05(2.5)$ & $5.00(2.0)$ \\
\hline & $2.5: 1$ & 800 & 47.00 (3.3) & $9800(4.0)$ & $22.17(1.8)$ & $4.12(3.0)$ \\
\hline & 3.0:1 & 800 & $56.11(5.0)$ & $11,544(3.2)$ & $20.02(1.7)$ & $3.08(1.0)$ \\
\hline \multirow[t]{4}{*}{$1 \% \mathrm{NaOH}$} & $1.0: 1$ & 1200 & 45.12 (3.8) & $9846(5.0)$ & 24.67 (2.6) & $7.00(2.1)$ \\
\hline & $1.5: 1$ & 1200 & $50.83(2.9)$ & 11,109 (3.0) & $23.02(1.8)$ & $5.01(1.2)$ \\
\hline & 2.0:1 & 1200 & $57.10(4.1)$ & $12,314(3.8)$ & $21.14(1.5)$ & $5.21(1.2)$ \\
\hline & $2.5: 1$ & 1200 & $64.25(3.0)$ & $13,444(4.4)$ & $16.65(1.2)$ & $4.22(1.0)$ \\
\hline
\end{tabular}




\section{Continued}

\begin{tabular}{|c|c|c|c|c|c|}
\hline 3.0:1 & 1200 & 73.45 (4.8) & 15,065 (4.1) & $15.01(2.1)$ & $3.98(0.9)$ \\
\hline 1.0:1 & 800 & 38.91 (3.1) & 7721 (4.9) & $26.88(2.4)$ & $6.92(2.1)$ \\
\hline $1.5: 1$ & 800 & 42.11 (2.9) & $9327(4.4)$ & $24.11(1.7)$ & $7.11(1.6)$ \\
\hline $2.0: 1$ & 800 & 48.61 (3.9) & $10,870(4.7)$ & $21.00(1.2)$ & $5.04(1.4)$ \\
\hline $2.5: 1$ & 800 & 53.55 (3.7) & 11,378 (3.8) & $18.42(1.3)$ & $3.81(1.7)$ \\
\hline $3.0: 1$ & 800 & $66.80(4.0)$ & 13,154 (3.0) & $16.30(1.1)$ & $3.04(1.2)$ \\
\hline
\end{tabular}

Reported values are the weighted average of four (4) tests per production mix. ( ) = Nos in parenthesis are the co-efficient of variations in \%. All test specimens were conditioned at $20^{\circ} \mathrm{C} \pm 2^{\circ} \mathrm{C}$ and $65 \% \pm 1 \%$ relative humidity for 2 weeks before test.

Table 4. Summary of factorial analysis showing the effects of manufacturing mix on properties of Bambusa vulgaris-cement composite panel.

\begin{tabular}{|c|c|c|c|c|c|c|c|c|c|c|}
\hline \multirow{4}{*}{ Source of variation } & \multirow{4}{*}{$\begin{array}{l}\text { Degree of } \\
\text { freedom }\end{array}$} & \multicolumn{9}{|c|}{ Mean square and F-values for panel properties } \\
\hline & & \multicolumn{4}{|c|}{ Mechanical properties } & \multicolumn{5}{|c|}{24 hrs horizontal water soak } \\
\hline & & \multicolumn{2}{|c|}{$\begin{array}{l}\text { Modulus } \\
\text { of rupture }\end{array}$} & \multicolumn{2}{|c|}{$\begin{array}{l}\text { Modulus } \\
\text { of elasticity }\end{array}$} & \multicolumn{2}{|c|}{$\begin{array}{c}\begin{array}{c}\text { Water } \\
\text { absorption }\end{array}\end{array}$} & \multicolumn{2}{|c|}{$\begin{array}{l}\text { Thickness } \\
\text { swelling }\end{array}$} & \\
\hline & & MS $\times 10^{4}$ & $\mathbf{F}$ & MS $\times 10^{10}$ & $\mathbf{F}$ & MS $\times 10^{4}$ & $\mathbf{F}$ & MS $\times 10^{4}$ & $\mathbf{F}$ & $\mathbf{F}_{\text {Tab }}$ \\
\hline \multicolumn{11}{|l|}{ Main effects } \\
\hline Cement/B. vulgaris mix ratio & 4 & 0.152 & $2.92^{* \mathrm{~K}}$ & 1.655 & $15.18^{* *}$ & 1.304 & $18.11^{* *}$ & 0.432 & $3.86^{* *}$ & 3.44 \\
\hline Soak treatment & 3 & 0.164 & $3.15^{* a}$ & 1.499 & $13.29^{* *}$ & 1.109 & $15.40^{* *}$ & 0.310 & $2.77^{* a}$ & 3.91 \\
\hline Density & 1 & 0.148 & $2.85^{\mathrm{NS}}$ & 2.617 & $24.01^{* *}$ & 0.405 & $5.63^{*}$ & 1.023 & $9.13^{* *}$ & 6.84 \\
\hline \multicolumn{11}{|l|}{ First order interaction } \\
\hline Mix ratio/density & 4 & 0.911 & $17.52^{* *}$ & 3.835 & $35.18^{* *}$ & 1.071 & $14.88^{* *}$ & 3.084 & $27.54^{* *}$ & 3.44 \\
\hline Mix ratio/soak treatment & 4 & 0.630 & $12.12^{* *}$ & 2.046 & $18.77^{* *}$ & 0.224 & $3.11^{* \mathrm{~K}}$ & 1.816 & 16.21 & 3.44 \\
\hline Soak treatment/density & 3 & 0.512 & $9.85^{* *}$ & 1.325 & $12.16^{* *}$ & 0.188 & $2.61^{* \mathrm{a}}$ & 0.301 & $2.69^{* a}$ & 3.91 \\
\hline \multicolumn{11}{|l|}{ Second order interaction } \\
\hline Mix ratio/density/soak treatment & 4 & 0.448 & $8.62^{* *}$ & 4.472 & $41.03^{* *}$ & 0.897 & $12.46^{* *}$ & 0.416 & $3.71^{* *}$ & 3.44 \\
\hline Error & 136 & 0.052 & - & 0.109 & - & 0.072 & - & 15.232 & 0.112 & - \\
\hline Total & 159 & - & - & - & - & - & - & - & - & - \\
\hline
\end{tabular}

${ }^{\text {NS }}$ Not significant at 0.05 level $\left(\mathrm{F}_{\mathrm{Tab}}=3.91\right) .{ }^{*}$ Significant at 0.05 level. ${ }^{* *}$ Significant at 0.01 level. ${ }^{*} \mathrm{~F}_{\mathrm{Tab}}=2.43$ at $5 \%$ level of significance. ${ }^{*} \mathrm{~F}_{\mathrm{Tab}}=$ 2.67 at $5 \%$ level of significance.

significant at $0.01 \%$ level of probability. This tends to suggest that MOE is a more sensitive measure of the importance of manufacturing variables on properties of wood/cement composites than MOR. It also goes to suggest that structural integrity as could be adjudged from compaction ratio and/or relative void volume play more significant roles in determining MOE of wood-cement composite panels. This later argument is in accord with the findings of Lingfei who corroborated properties with internal structures of bamboo/cement composite panels using X-ray diffraction (XRD), Thermo-gravimetric differential analysis (TG-DTA) and Scanning Election Microscopy (SEM) [20].

\subsection{Physical Properties}

\subsubsection{Water Absorption (WA)}

The cement/B. vulgaris composite panel's WA properties after a 24 hrs horizontal water soak ranges from an 
average low of $15.01 \%$ to a max $36.11 \%$ (see Table 3) for all panel types produced. This is within the range reported in the literature for wood-cement composites of similar densities made from a wide range of wood/lignocellulosic furnish and treatments [7] [37]. The effects of all variable production mix used in the study (density, soak treatment and cement: wood ratio) on WA as well as those of their first order and third order interactions were all found significant at $0.01 \%$ level except for the effects of cement: wood mix ratio/soak treatment and soak treatment/density which were each found significant at the $0.05 \%$ level of probability in a factorial analysis. The implication is that higher cement content and density are possibly the more effective means of reducing WA even though all the variables are significant. Higher cement: wood mix ratio will ensure strong interparticle bond and at same time reduce moisture absorption by blocking the diffusional pathways while increase in density will reduce void volume within the composite [8] [9] [30].

\subsubsection{Thickness Swelling (TS)}

The percentage thickness swelling (\% TS) due to a 24 hrs horizontal water soak is in Table 3. The mean TS ranges from $3.04 \%$ to $12.72 \%$. The TS is within the range reported in the literature of properties of wood-cement composites using a wide variety of lignocellulosic sources but of similar density range [7] [14] [28] [37]. Factorial analysis indicates that the effects of soak treatment and the interaction between soak treatment with density on TS was significant at $0.05 \%$ level while the effects of each of the other production variables and all other possible interaction levels (except soak/density) were significant at $0.01 \%$ level (Table 4). It does appear that a greater synergy is achieved using a combination of mix ratio and density in reducing TS. A direct relationship between panel density and TS exists while an inverse relationship between cement: wood mix ratio and TS exists. The logic here is that higher composite panel density at same mix ratio will lead to a higher TS if other factors are same. Conversely, increase in the cement: wood mix ratio at a constant density will reduce TS as mix ratio was increased. This is because the efficacy of the inter particle bond will help to reduce water absorption and consequently the magnitude of TS. However, all the three variables are effective means of reducing TS as the third order level of interactions shows.

\section{Conclusion}

The studies have proved that B. vulgaris grown in Anambra river basin, southeast, Nigeria can be used to produce cement composite panels of acceptable properties as all panels produced met property requirements of ANSI-208-1 and ANSI-208-2; BS 5669 and MS 934 [33]-[36]. The effects of each of the production mix (soak treatment/density/cement-B. vulgaris mix ratio) were all found significant as their third order levels of interaction on MOR, MOE, TS and WA were all significant at the $0.01 \%$ level of probability in a factorial analysis. The composite panels made in this study will be suitable for load bearing constructions, partitioning, and flooring especially if the composite will not be subjected to long exposure to direct contact with water/hydrophilic fluids. The production of $B$. vulgaris composites will be sustainable in view of its rapid biomass production, and environmental friendliness as it could reduce pressure on forest trees and has high employment generation potentials in developing economies.

\section{References}

[1] Kuriakose, S., Deviprasad, V. and Vaisakh, V.G. (2012) Mechanical Behaviour of Coir Reinforced Polyester Composite-An Experimental Investigation. International Journal of Emerging Technology and Advanced Engineering, 2, 751-757.

[2] Fuwape, J.A. (2001) The Impacts of Forest Industries and Wood Utilization on the Environment. Journal of Tropical Forest Research, 17, 78-90.

[3] Chen, X.H. (2000) The Sustainable Development of Wood Industry for the 21st Century. Forest Products and Industry, 26, 13.

[4] Raw Materials Research and Development Council (RMRDC) (1996) Report on the Techno-Economic Survey of the Multi-Disciplinary Task Force on Pulp, Paper Products, Printing and Publishing Sector, Lagos, 33.

[5] Lebel, P.W., Gunther, J., Webb, W., Clark, W.C., Food, B., Fasehun, F.E., Sanwo, S.K. and Bada, S.O. (1994) Review of Wood-Based Sector in Nigeia. Final Report Presented to FORMECU, Federal Ministry of Agric and Natural Resources, Abuja.

[6] Agnihotri, S., Dutt, D. and Tyagi, C.H. (2010) Complete Characterization of Bagasse of Early Species of Saccharum 
officinerum —CO 89003 for Pulp and Paper Making. Bioresources, 5, 1197-1214.

[7] Erakhrumen, A.A., Areghan, S.E., Ogunleye, M.B., Larinde, S.L. and Odeyale, O.O. (2008) Selected Physico-Mechanical Properties of Cement Bonded Particlboard Made from Pine (Pinus caribaea M.) Mixture. Scientific Research and Eassy, 3, 197-203.

[8] Jorge, F.C., Pereira, C. and Ferreira, J.M.F. (2004) Wood-Cement Composites-A Review. Holz als Roh- und Werkstoff, 62, 370-377. http://dx.doi.org/10.1007/s00107-004-0501-2

[9] Youngquist, J.A. (1999) Wood-Based Composites and Panel Products. In: Wood Handbook: Wood as an Engineering Material. General Technical Report FPL-113, USDA, Forest Service, Forest Products Laboratory, Madison, Chapter 10, 1-31.

[10] Jayabal, S., Sathiyamurthy, S., Loganathan, K.T. and Kalyanasundaram, S. (2012) Effect of Soaking Time and Concentration of $\mathrm{NaOH}$ Solution on Mechanical Properties of Coir-Polyester Composites. Bulletin of Materials Science, $\mathbf{3}$, 567-574. http://dx.doi.org/10.1007/s12034-012-0334-2

[11] Bamisaye, J.A. (2007) Cement Bonded Particle Board Production from Rice Husk in Southern Nigeria. Journal of Engineering and Applied Sciences, 21, 183-185.

[12] Chew, L.T., Sudin, R. and Kasim, J. (1992) Bambusa vulgaris for Urea and Cement-Bonded Particleboard Manufacture. Journal of Tropical Forest Science, 4, 249-256.

[13] Badejo, S.O.O. (1987) An Investigation on the Influence of Cement Binder Content on Properties of Cement-Bonded Particle Board from Four Tropical Hardwoods. The Malaysian Forester, 50, 105-120.

[14] Moslemi, A.A. and Pfister, S.C. (1987) The Influence of Cement-Wood Ratio and Cement Type on Bending Strength and Dimensional Stability of Wood-Cement Composite Panels. Wood and Fiber Science, 19, 165-175.

[15] Onuorah, O.E. (2005) Properties of Fiberboards Made from Oil Palm (Elaeis guineensis) Stem and/or Mixed Tropical Hardwood Sawmill Residues. Journal of Tropical Forest Science, 17, 497-507.

[16] (2009) Environmental Bamboo Foundation Why Bamboo. www.bambooman.com.au/bambootreatment/ebf.php

[17] Renuka, D.M., Poornima, N. and Guptan, P.S. (2007) Bamboo-The Natural, Green and Eco-Friendly New-Type Textile Material of the $21^{\text {st }}$ Century. Journal of the Textile Association, 221-224.

[18] Fangchun, Z. (1999) The 20 ${ }^{\text {th }}$ Century in Retrospect for Bamboo Trade and Prospects for the $21^{\text {st }}$ Century. Journal of Bamboo Research, 4.

[19] Claudio, H., Soares, D.M., Vinicius, G.C. and Mario, R.S. (2007) Production and Properties of Medium Density Wood-Cement Boards Produced with Oriented Strands and Silica Fume. Maderas Cienciay Technologia, 9, 105-115.

[20] Ma, L.F. (2000) Manufacture of Bamboo-Cement Particleboard. Proceedings of the International Symposium on Trends of Wood Research and Utilization, Tokyo, 8.

[21] Lee, A.W.C. and Short, P.H. (1989) Pretreating Hardwood for Cement-Bonded Excelsior Board. Forest Products Journal, 39, 68-70.

[22] Keay, R.W.I., Onochie, C.F.A. and Standfield, D.O. (1964) Nigerian Trees. Vols. I \& II. Federal Department of Forestry Research, Ibadan.

[23] Liese, W. (1986) Anatomy and Properties of Bamboo. GTZ Publication, 196-207.

[24] Technical Association of Pulp and Paper Industry (TAPPI) (1998) Test Methods. TAPPI Press, Atlanta, 1998.

[25] Akpabio, U.D.I. (1989) The Effects of Mechanical Treatment and Blending of Tropical (Nigerian) Wood Pulps on Paper Properties. Nigerian Journal of Technical Education, 6, 32-43.

[26] American Society for Testings and Materials (1998) Standard Test Methods for Evaluating Properties of Wood-Based Fiber and Particle Panel Materials. ASTM D1037-98, Annual Book of Standards, Philadephia.

[27] Miller, I. and Freud, E.J. (1975) Probability and Statistics for Engineers. Prentice-Hall Inc., Englewood Cliffs.

[28] Asasutjarit, C., Hirunlabh, J., Khedari, J., Daguenet, M. and Quenard, D. (2005) Coconut Coir Cement Board. International Conference on Durability of Building Materials and Components, Lyon, 17-20 April 2005.

[29] Hunter, W.R. (2001) Nonwood Plant Fiber Characteristics. Hunter Consult Incorporated, Ottawa, 4.

[30] Kelly, W.M. (1997) Critical Literature Review on Relationships between Processing Parameters and Physical Properties of Particleboard. General Technical FPL-10, USDA.

[31] Ogunsile, B.O. and Uwajeh, C.F. (2009) Evaluation of the Pulp and Paper Potentials of a Nigerian Grown Bambusa vulgaris. World Applied Sciences Journal, 6, 536-541.

[32] Olorunnisola, A.O. (2007) Effects of Particle Geometry and Chemical Accelerator on Strength Properties of RattanCement Composite. African Journal of Science and Technology, 8, 22-27.

[33] American National Standards Institute (1994) National Hardwood Association Standard for Medium Density Fiber- 
board (MFD). ANSI A 208-2-1994, Gaithersburg.

[34] American National Standards Institute (1993) National Particle Board Association Standard for Particleboard. ANSI A 208-1-1993, Gaithersburg.

[35] British Standard Institution (1979) Specifications for Wood Chipboard and Methods of Test for Particleboard. BS 5669:1979. British Standard Institution, London.

[36] Malaysia Standard Institute-MS 934 (1984) Malaysian Standard Specification for Wood-Cement Board. SIRIM, Malaysia.

[37] Oyagade, A.O. (2000) Thickness Swelling Components and Water Absorption of Cement-Bonded Particleboards Made from Gmelina Wood, Bagasse and Coconut Husk. Nigerian Journal of Forestry, 30, 10-14. 
Scientific Research Publishing (SCIRP) is one of the largest Open Access journal publishers. It is currently publishing more than 200 open access, online, peer-reviewed journals covering a wide range of academic disciplines. SCIRP serves the worldwide academic communities and contributes to the progress and application of science with its publication.

Other selected journals from SCIRP are listed as below. Submit your manuscript to us via either submit@scirp.org or Online Submission Portal.
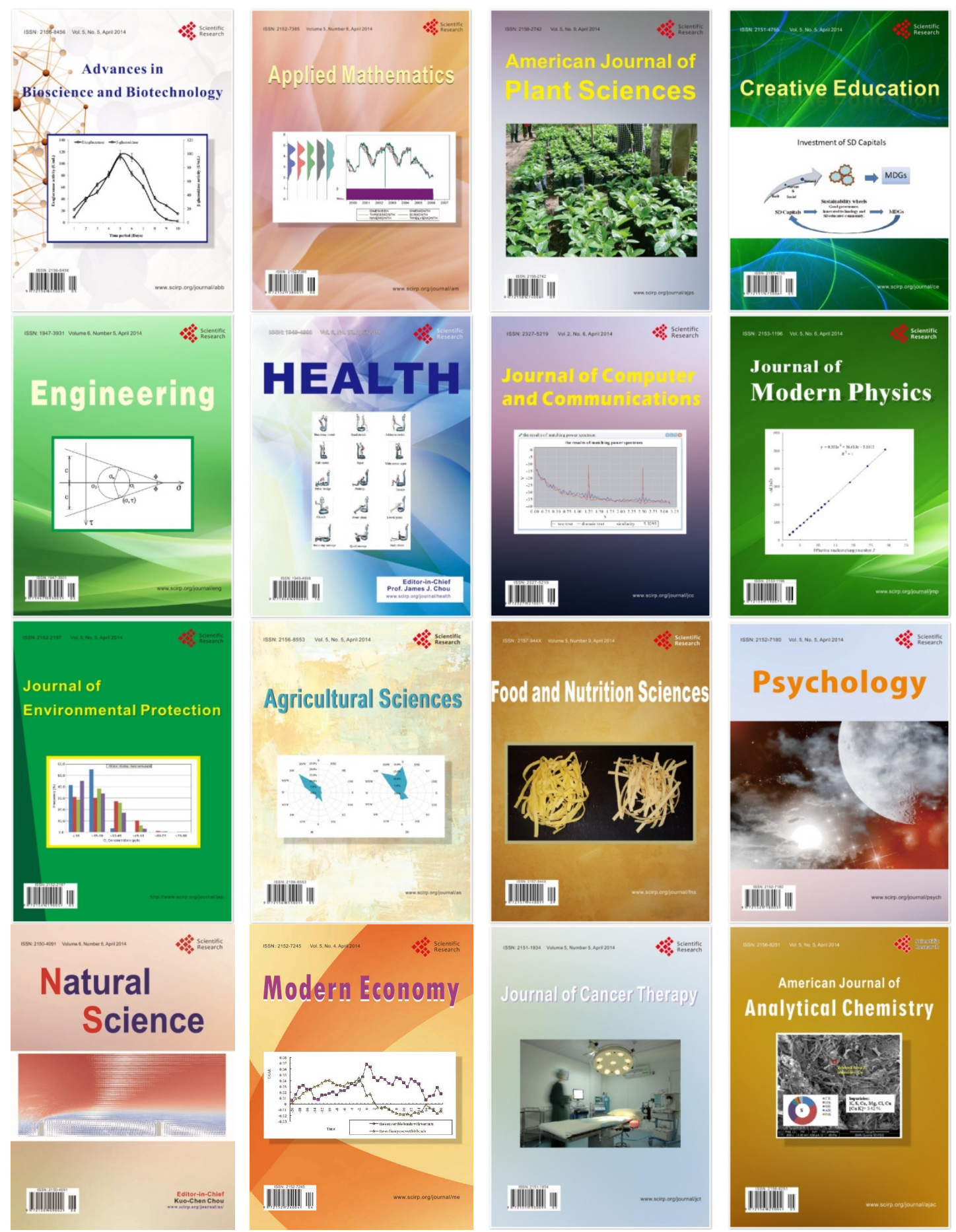